\title{
DEVEM OS JUÍZES BRASILEIROS SEREM MAIS EMPÁTICOS?
}

\author{
Sergio Nojiri* ${ }^{1}$ \\ Camila Raposo Batista ${ }^{2}$
}

\section{RESUMO}

O artigo analisa, por meio de revisão bibliográfica, argumentos favoráveis e contrários à necessidade e utilização da empatia na tomada de decisão judicial, investigando seus efeitos na imparcialidade do juiz. Para tal, realiza distinção entre empatia afetiva e sua modalidade cognitiva. Considera a realidade do judiciário brasileiro através de dados do Conselho Nacional de Justiça (2014 e 2018) e, em razão da composição da classe de magistrados encontrada dentro dos critérios selecionados, conclui pela necessidade da utilização da empatia cognitiva a fim de que as decisões sejam imparciais, na medida que considerem diversos pontos de vista.

PALAVRAS-CHAVE: Empatia judicial; Empatia cognitiva; Tomada de decisão; Imparcialidade; Perfil dos magistrados brasileiros

\section{SHOULD BRAZILIAN JUDGES BE MORE EMPATHETIC?}

\begin{abstract}
The article analyzes, through a bibliographic review, arguments favorable and contrary to the need and use of empathy in judicial decisions making, searching for its effects in judge's impartiality. Therefore, realizes the distinction between affective empathy and its cognitive modality. It considers the reality of the Brazilian judiciary through data of the Conselho Nacional de Justiça (2014 and 2018) and, due to the composition of the class of magistrates found within the selected criteria, it concludes for the need to use cognitive empathy in order to obtain impartial decisions, as they consider diverses point of view.
\end{abstract}

KEY-WORDS: Judicial empathy; Cognitive empathy; Decision making; Impartiality; Profile of the brazilian magistrates

\section{INTRODUÇÃO}

O presente artigo busca realizar uma intersecção entre a composição da magistratura brasileira e a necessidade da utilização da empatia judicial sob uma perspectiva cognitiva. $\mathrm{O}$ perfil do magistrado brasileiro já é estudado há anos por pesquisas que investigam seus mais

\footnotetext{
*1 Professor Doutor de Graduação e Pós-graduação da Faculdade de Direito de Ribeirão Preto da Universidade de São Paulo, FDRP-USP, endereço postal: Universidade de São Paulo, Faculdade de Direito-Ribeirão Preto, Rua Prof. Aymar Baptista Prado, 835 - Campus da USP de Ribeirão Preto, Vila Monte Alegre 14040-906 Ribeirão Preto, SP - Brasil, endereço eletrônico: nojiri@usp.br

*2 Mestranda em Direito pela Faculdade de Direito de Ribeirão Preto da Universidade de São Paulo, FDRP-USP, endereço postal: Universidade de São Paulo, Faculdade de Direito-Ribeirão Preto, Rua Prof. Aymar Baptista Prado, 835 - Campus da USP de Ribeirão Preto Vila Monte Alegre 14040-906 - Ribeirão Preto, SP - Brasil, endereço eletrônico: camila.raposo.batista@usp.br
} 
diversos elementos (cita-se, exemplificativamente, BONELLI, 2011) como sua origem demográfica, sua idade, origens sociais, gênero e a trajetória de sua família dentro do poder judiciário. Nestas pesquisas, é possível verificar um padrão de quem são os juízes brasileiros no que diz respeito à estas características identificadoras ou ainda uma homogeneidade na forma de decidir da magistratura. Para entender a composição desta classe na atualidade será realizada, de forma simplificada, análise com os dados mais recentes sobre os magistrados disponibilizados pelo Conselho Nacional de Justiça, buscando novamente traçar um padrão dentro da magistratura brasileira.

Desta análise, surgem dois cenários a serem estudados. Inicialmente, havendo esta homogeneidade que reúne os julgadores ${ }^{3}$ não representativa de diversas camadas da sociedade brasileira, busca-se entender como pode haver julgamentos que considerem pontos de vista distintos daqueles que julgam. Ou seja: havendo um rol de características predominantes nos juízes (o que será analisado no artigo), como auxiliá-los a compreender demandas propostas por diversas partes que além de padrões distintos, possuem também experiências e vivências diversas? Um outro cenário, que considera a diversidade na composição do judiciário, mas entende que suas diferenças acabam sofrendo um silenciamento, incita a seguinte questionamento: quando considerada magistratura brasileira como classe heterogênea como devolver a voz àqueles que a silenciaram de forma a permitir que suas diferenças reflitam na maneira de julgar? Não se incluem nestes questionamentos a compreensão pura do texto da lei, mas sim o entendimento das situações que se apresentam para seu julgamento como um todo. E justamente neste cenário das diversas demandas judiciais, muito mais amplo e heterogêneo, será estudada como a empatia, em sua vertente cognitiva, é necessária para haver um julgamento imparcial e justo.

A fim de realizar esta análise o artigo possui três partes. Na primeira parte, argumentos contrários à utilização da empatia dentro do contexto da tomada de decisão judicial serão apresentados, com destaque ao pensamento de Noel Struchiner, pesquisador brasileiro que trata do tema, também aos entendimentos de Prinz, com quem Struchiner dialoga. Em seguida, entendendo a empatia como o recurso necessário para haver a neutralidade judicial, será apresentado o pensamento de alguns expoentes, como Colby, Lee e Bandes. Ao final, será analisada a situação do judiciário nacional, em que pese sua

\footnotetext{
${ }^{3}$ Destaca-se que a homogeneidade mencionada se refere exclusivamente à predominância de determinadas características verificadas dentre os juízes na análise realizada a partir dos dados do CNJ.
} 
composição dentro das concepções de empatia apresentadas, concluindo se é ou não necessário que os juízes brasileiros sejam mais empáticos a fim de tomarem decisões justas.

$\mathrm{O}$ artigo, em seu aspecto metodológico, vale-se de levamento bibliográfico acerca das concepções de empatia e de argumentos favoráveis e contrários à sua presença no contexto da tomada de decisão legal. Também será realizada breve análise acerca da composição da magistratura brasileira, utilizando-se dados referentes a classe de magistrados levantados pelo último Censo do Poder Judiciário realizado pelo Conselho Nacional de Justiça no ano de 2013 e publicado em 2014 e pela pesquisa que traça o Perfil Demográfico dos Magistrados Brasileiros realizada também pelo CNJ no ano de 2018. Assim, se dará o tratamento metodológico ao material selecionado para o presente artigo que objetiva entender os efeitos da empatia judicial na tomada de decisão e verificar sua necessidade dentro do contexto da magistratura brasileira.

\title{
2 EMPATIA COMO PROBLEMA
}

O polêmico, e ainda assim antigo ${ }^{4}$, significado de empatia pode ser entendido como conceito amplo que engloba diversas definições, as quais surgem de várias acepções do termo (LOW, 2018).

Em levantamento recente, Cuff et al (2014) sumarizaram um total de 46 conceitos distintos que podem ser atribuídos à empatia. Confrontaram as definições mais relevantes, buscando distinguir se é: cognitiva ou afetiva; congruente ou incongruente com o observado; sujeita (ou não) a estímulos; distinguível ou fundida com o outro; um traço ou um estado; se possui um resultado comportamental e se é automática ou controlável. Os autores, após o levantamento e análise, optaram por criar uma concepção autoral para o termo:

\begin{abstract}
Empatia é uma resposta emocional (afetiva), dependente da interação entre as capacidades dos traços e as influências do estado pessoal. Os processos empáticos são eliminados automaticamente, mas também são moldados por processos de controle "de cima para baixo". A emoção resultante é semelhante à percepção (experimentada diretamente ou imaginada) e compreensão (empatia cognitiva) da emoção-estímulo, com o reconhecimento de que a fonte da emoção não é do sujeito empático. (CUFF ET AL, 2014, p. 150, tradução nossa) ${ }^{5}$
\end{abstract}

\footnotetext{
${ }^{4}$ Gary Low, em seu artigo intitulado Emphatic plea for the empathic judge sustenta que o termo "empatia é tão antigo quanto Aristóteles". (2018, p. 105, tradução nossa)

5 Trecho original: "Empathy is an emotional response (affective), dependent upon the interaction between trait capacities, and state influences. Empathic processes are automatically elicted but are also shaped by top-down
} 
Não somente, mas também em decorrência da pluralidade de definições existentes para o termo, é esperado e de fato ocorre que seus múltiplos significados impliquem em visões diametralmente opostas acerca de sua utilização. Tal situação gera grande debate sobre os contextos e formas nas quais a empatia pode estar presente.

Para além de seu uso em situações do cotidiano em suas diversas acepções, busca-se analisar sua adequação ao meio judiciário, para, em seguida, considerá-la na realidade do Brasil. Sobre sua aplicação por operadores do direito, há, novamente, grande dissenso, sobretudo no tocante à manutenção da imparcialidade do juiz empático face às situações que se apresentam a seu crivo. A academia se divide em defensores dos juízes empáticos e em ferrenhos críticos daqueles que fazem uso deste recurso.

Noel Struchiner, professor de Direito e Filosofia na Pontifícia Universidade Católica do Rio de Janeiro, é abertamente contrário à empatia como fonte para o processo de decisão moral e legal, filiando-se aos pensamentos de Jesse Prinz, professor de Filosofia na Universidade da Cidade de Nova Iorque. Struchiner, ciente de que sua posição parece severa e contraintuitiva, apresenta os motivos para adotá-la em seu artigo denominado "No Empathy Towards Empathy: Making the Case for Autistic Decision-Making”, publicado em 2011.

O autor, inspirado na concepção de Prinz (2011a), define que a empatia é o assimilar das emoções alheias. A partir desta compreensão, biparte este sentimento em suas facetas cognitiva e afetiva, assim como o faz outros pesquisadores, como por exemplo Susan Bandes (2011) e Thomas Colby (2012). A cognitiva (defendida por aqueles a favor de sua utilização na tomada de decisão, como se verificará em seguida) seria o entendimento do que o outro sente, desvinculado, contudo, do sentir em si o que é do outro. Já a modalidade afetividade implicaria, necessariamente, em sentir o que o outro sente, criando-se um vínculo de afetividade e, portanto, de perda de imparcialidade.

Prinz (2011a) entende que a empatia não é necessária para a realização de julgamentos morais, incluindo motivações morais ou ainda desenvolvimentos morais, e que possui vieses inerentes, defendendo, inclusive, a preocupação como um sentimento mais adequado e que consegue superpor as falhas do sentimento empático. O autor (PRINZ, 2011b)

control processes. The resulting emotion is similar to one's perception (directly experienced or imagined) and understanding (cognitive empathy) of the stimulus emotion, with recognition that the source of the emotion is not one's own." p. 150 
sintetiza que é limitada, essencialmente em virtude lhe faltar tanto a força motivacional necessária (o que sentimentos como a raiva provém), quanto de ser essencialmente seletiva.

Struchiner (2011) apresenta, exemplificativamente, um rol de situações nas quais a empatia, limitada, figura como um obstáculo à tomada de decisão moral. Destacam-se algumas situações: quando sentida de forma muito intensa, seria um dificultador da ação mais adequada do agente em face da vítima em virtude de causar um grande incomodo naquele que a sente. Assim, o autor passa a pensar em si e não na vítima, podendo inclusive deixar de agir perante ela: “[...] a empatia intensa pode gerar tamanha angústia que se perde o foco na vítima e passa-se a preocupar-se consigo mesmo. Isso pode levar à uma inação face à vítima"6. (STRUCHINER, 2011, p. 16, tradução nossa). Assim, num contexto de tomada de decisão no qual o foco não deve ser o sentimento do juiz perante a vítima, mas sim a forma mais justa de resolver a demanda, este desvio poderia acabar ocorrendo em razão do sentimento empático. No exemplo narrado ocorreria a prevalência da empatia em sua modalidade afetiva. Não haveria simplesmente a compreensão do que a vítima sente, pelo contrário, o sentimento e dor alheia passariam a ser, também, do agente que as presencia/imagina e passa a senti-las. Neste tipo de situação, com excesso do sentimento empático, ocorreria então comprometimento da capacidade de agir, e, portanto, de julgar de forma imparcial o que se passa.

O autor exemplifica outra situação na qual consideraria sua utilização pelo julgador como inadequada: quando sua presença faz com que seja tomada uma decisão que não necessariamente atende ao melhor interesse da parte. No caso concreto, Struchiner menciona a realidade brasileira. Aduz ser cada vez mais frequente que as pessoas entrem com ações judiciais a fim de obter tratamentos e remédios de alto custo que não estejam comtemplados pelo Sistema Único de Saúde (SUS). Nesta situação, os juízes que se tornarem empáticos com a demanda podem fornecer decisão judicial autorizando o tratamento sem haver certeza de que é o mais adequado para a parte. (STRUCHINER, 2011) Novamente, o sentir pelo outro seria um óbice ao melhor raciocínio do julgador, eis que contaminado por dadas emoções. Assim, a empatia que afasta o juiz de sua racionalidade seria maléfica ao processo de tomada de decisão judicial.

Estes impeditivos da melhor tomada de decisão face à vítima, também podem se originar na correlação existente entre empatia e alguns vieses citados por Struchiner (2011) e

\footnotetext{
${ }^{6}$ No original: "[...] intense empathy may generate such a large distrerss that one looses focus on the victim and starts worryng about oneself. This can lead to inaction towards the victm".
} 
Prinz (2011a). São eles o viés da similaridade, da fofura e do "aqui e agora". Estes vieses, de forma bastante breve e simplificada, fazem com que se empatize somente por seus semelhantes, pelo que é mais meigo e pelo que é mais concreto, respectivamente. No contexto judicial, podem levar as questões jurídicas a serem decididas com base na preferência, na hipótese de os juízes não estarem cientes deste potencial desvio. Nesta lógica, a empatia pode se tornar seletiva se ocorrer em virtude de predileções pessoais geralmente arbitrárias e preexistentes (STRUCHINER, 2011). Destaca-se que tal situação tem maior propensão a ocorrer quando não há conhecimento ou esforço do magistrado de impedir o julgamento influenciado por estes desvios.

Seria, então, um elemento perigoso na tomada de decisão, em virtude dos vieses que pode trazer consigo. Outras emoções poderiam ser mais relevantes no tocante à moralidade (como a raiva e a culpa). Compadecer-se em virtude da empatia, sobretudo quando se verificam questões que maculam a moral, não seria a melhor posição para com a vítima (PRINZ, 2011b).

Observa-se que os principais óbices apresentados acerca da utilização da empatia na tomada de decisão judicial consideram sua modalidade afetiva, a qual implica na perda de imparcialidade. Contudo, como será exposto, há uma outra forma de compreendê-la e aplicála neste contexto jurídico que além de adequada, se faz necessária para a verificação dos diversos pontos de vista, o que, na realidade da magistratura brasileira, se faz ainda mais necessário em virtude de sua composição.

\section{EMPATIA COMO SOLUÇÃO}

Em outra posição, existem aqueles defensores da empatia, aqui em sua modalidade cognitiva, como essencial para a realização da Justiça. Serão apresentados os principais argumentos de Thomas Colby (2012), expostos em artigo denominado "In defense of judicial empathy", onde o autor traça uma linha argumentativa que se inicia com a definição do termo em sua concepção e termina com algumas soluções para que sua utilização seja facilitada. Rebecca Lee, cujo pensamento será exposto em seus pontos centrais, é outra expoente desta posição que vincula a utilização da empatia como elemento garantidor da imparcialidade judicial. No seu artigo "Judging Judges: Empathy as the Litmus Test for Impartiality" publicado em 2013, a autora expõe as razões pelas quais a empatia é necessária, 
exemplificando em casos de discriminação no contexto das relações empregatícias e, por fim sugere formas de requerer e melhorar sua aplicação.

Especificando a definição mais ampla de Cuff et al (2014) anteriormente citada, Colby (2012) inicialmente vale-se de uma definição de dicionário para caracterizar empatia, dada a complexidade do termo. Para o autor, esta é entendida como uma capacidade de compreensão de pontos de vista que não implica, necessariamente, na perda de neutralidade por parte de quem a sente. Inclusive, no tocante à perda de neutralidade, o autor considera que esta seria decorrente da simpatia ${ }^{7}$, que por sua vez faz com que se sinta pelo outro. Percebe-se que o entendido como modalidade afetiva é chamado por Colby de simpatia. Assim, pela simpatia, o indivíduo não somente compreende com sua capacidade cognitiva o que o outro experienciou, mas envolve seus sentimentos à medida que sente por ele.

Colby (2012) vale-se da concepção cognitivista, uma vez que desvincula desta capacidade o envolvimento afetivo e emocional daquele que é seu alvo. De início, já se afasta dos principais argumentos utilizados pelas partes contrárias a seu uso, eis que as críticas costumam se voltar à face afetiva. Aqui, esta parte da empatia sequer é compreendida como sendo este termo, pois o autor a define como simpatia.

Lee (2013), por sua vez, entende a empatia de forma semelhante à Colby no tocante à compreensão do ponto de vista alheio, incluindo, porém, seu aspecto afetivo, o que não figura como característica que desabone sua presença. Para a autora, sobretudo em julgamentos nos quais as partes estão em posições distintas dos juízes em termos de oportunidades e expectativa social seu uso é ainda mais relevante. Referenciando Colby, Lee conclui que a empatia seria, então, o que torna o juiz capaz não somente de compreender os impactos de sua decisão sobre as partes, como também as origens humanas do que causou a demanda que se apresenta.

Neste sentido, Colby (2012) discorre que: “a empatia nos centros de julgamento é uma habilidade para verdadeiramente compreender a dimensão humana do caso - os efeitos que a determinação judicial causarão em todas as pessoas que serão afetadas por eles” (COLBY, 2012, p. 164), bem como “A empatia ajuda a resolver quais problemas legais de cada litigante devem prevalecer, porque a questões legais podem não serem respondidas sem que se compreenda a forma com que os litigantes serão impactados pela decisão" (COLBY,

\footnotetext{
${ }^{7}$ Bandes (2011) difere ainda a empatia em sua modalidade afetiva "sentir com o outro" da simpatia. Para a autora, este último sentimento faz com que se escolham lados e eventualmente que se haja a favor do bem-estar de uma das partes, o que não ocorre quando se sente empatia.
} 
2012, p. 1965) Explicita, então, a sua utilização como a ferramenta adequada para a real compreensão da demanda em sua dimensão humana e considerando os efeitos que uma decisão judicial pode causar. Portanto, quando se faz presente é o meio de encontrar, de fato, a solução para o litígio.

Contudo, esta compreensão de um juiz empático se opõe ao imaginário geral do que seria o julgador ideal (e irreal). Gary Low, em artigo intitulado "Empathic plea for the empathic judge" sustenta, inicialmente, que a figura do juiz "mítico, quase platônico, filosófico e capaz de filtrar evidências e fatos com eficiência implacável e aplicar regras legais para alcançar resultados objetivamente justos” (LOW, 2018, parágrafo 5, tradução nossa $)^{8}$ não existe, pois, a subjetividade do juiz e de seus julgamentos são inevitáveis. Entretanto, esta crença segue permeando o senso comum acerca da figura do juiz, como se o processo de se tornar magistrado, de vestir a toga eliminasse a susceptibilidade do magistrado frente à vieses e fragilidades, distinguindo-os dos outros seres humanos e lhes conferindo atributos quase mágicos. (NEGOWETTI, 2014)

Necessário destacar que quaisquer manifestações da subjetividade do juiz, entendendo-se as emoções como uma de suas expressões, são malvistas e coibidas pela legislação, que se vale de instrumentos como o afastamento por suspeição para remediar esta situação:

\begin{abstract}
A probabilidade da manifestação de emoções negativas pelo juiz (tais como raiva ou ódio) justiça o seu afastamento por suspeição, quando uma das partes num processo sob sua jurisdição for seu inimigo capital. $\mathrm{O}$ juiz afetado pelas emoções se tornaria pouco confiável, pois estaria propenso a descumprir seu dever de imparcialidade. Em suma, o protótipo de virtude judicial consiste na impassibilidade diante das emoções e na estrita adesão aos argumentos racionalmente justificáveis. (STRUCHINER, TAVARES, 2014, p. 111)
\end{abstract}

Argumenta-se, contudo, que embora expressamente coibida, a influência da subjetividade é inevitável, eis que nem sempre se manifesta de forma nítida suficiente a ponto de ser percebida, embora, como defendido por Low (2018), esteja sempre presente. Decisões parciais e tomadas com base na análise não neutra das situações são realizadas pelos julgadores, que utilizam, de forma consciente ou inconsciente de sua subjetividade.

\footnotetext{
${ }^{8}$ No trecho original: "[...] mythical quasi-Platonic philosopher-king systematically sifting through evidence and facts with ruthless efficiency and applying legal rules coldly to achieve objectively fair outcomes." Parágrafo 5
} 
Tal situação, que já pressupõe o distanciamento da figura irreal do julgador inevitavelmente objetivo, pode se dar deliberadamente, como resultado de uma interpretação incorreta ou ainda pelo ignorar de informações relevantes e considerar algumas que sejam legalmente irrelevantes. A solução para este problema causado pela subjetividade que ora se filia à uma perspectiva, ora à outra, reside justamente na origem destas filiações: a empatia. (LOW, 2018).

Considerando que a subjetividade é inerente aos humanos e, obviamente aos julgadores, esta característica é o que os direciona a um julgamento mais parcial em virtude das aproximações mencionadas acima. O juiz mais capacitado seria aquele que possui a técnica adequada para realizar o afastamento das implicações subjetivas, pois imparcial e neutro. Assim, consegue analisar o caso tanto da ótica que não lhe seria automática, quanto da que imediatamente se apresenta aos seus olhos. Ou seja, o magistrado, que possui a habilidade empática de compreensão do ponto de vista de todos os envolvidos, consegue evitar a aplicação da legislação/doutrina/jurisprudência mais adequada às suas preconcepções, mas não ao caso concreto. Em outros termos: o julgador empático é o que julga de forma mais justa.

Justamente por esta capacidade de transitar entre as situações, não haveria comprometimento da imparcialidade, muito menos a predileção por um grupo específico, haja vista que o julgador não ficaria fixo em um polo apresentado:

Um juiz que exercita a habilidade de empatizar vai certamente o fazer com o pobre, o fraco e o vulnerável. Mas também vai sentir empatia com o rico, o poderoso e o mais forte. Um juiz empático irá entender a perspectiva tanto do homem inocente que foi erroneamente detido pela polícia, quanto do policial que teve que fazer um rápido julgamento quando vidas parecem estar em risco. Vai compreender a perspectiva de ambos que foram lesados pelo seguro que negou cobertura por sua perda e a avalição cética da reinvindicação que estava preocupado em evitar fraudes e conter custos. Vai compreender a perspectiva tanto do paciente que teve um diagnóstico errado e do médico que estava certamente preocupado com os custos e riscos de pedir testes adicionais (COLBY, 2012, p. 1964, tradução nossa) ${ }^{9}$

\footnotetext{
${ }^{9}$ Trecho original: "A judge who exercises the ability to empathize will surely do so with the poor, the weak, and the little guy. But she will also empathize with the rich, the powerful, and the big guy. An empathic judge will understand the perspective of both the innocent man who was mistakenly detained by the police and the police officer who had to make a snap judgment when lives appeared to be at risk. She will understand the perspective of both the aggrieved insured who was denied coverage for her loss and the skeptical claims adjustor who was concerned with avoiding fraud and containing costs. She will understand the perspective of both the dying patient who was misdiagnosed and the doctor who was rightly concerned with the costs and risks of ordering additional tests."
} 
Necessário destacar ressalva realizada por Low acerca da capacidade empática. Para além da possibilidade de livre trânsito do juiz por dentre as perspectivas das partes, este deve estar atento a fim de não incorrer nos excessos de empatia, o que Struchiner também indica como um ponto desfavorável ao seu uso. Logo, se torna possível a real melhora do processo de tomada de decisão judicial, sem que se incorra em excesso que pode ser responsável pelo julgamento com vieses (LOW, 2018).

Esta capacidade, porém, é mais facilmente exercida quando se dá com aqueles semelhantes a quem decide ${ }^{10}$, o que já foi exposto anteriormente como manifestação do viés da similaridade. Analisar situações de pontos de vista que não se costuma vivenciar requer que o indivíduo se imagine vivendo dada situação, demandando, necessariamente, um esforço muitas vezes não automático de quem julga para se atentar à tal fato (NEGOWETTI, 2014).

Uma forma de remediar, ainda que não completamente, este viés que a empatia eventualmente acarreta pode se dar por meio do uso da imaginação e da aproximação entre situações vividas pelo julgador e apresentadas pelos casos, verdadeiro esforço cognitivo de compreensão de experiencias sob diferentes perspectivas. Estes são meios de ampliar a visão limitada de mundo, diminuindo os pontos cegos, que são aqueles onde automaticamente se tem dificuldade em considerar, daquele que julga. Ou seja, são formas de expandir o horizonte do que será considerado relevante pelo juiz. Um dos recursos possíveis para, individualmente, melhorar esta capacidade de compreensão de realidades distintas seria a leitura de obras de ficção e até mesmo biográficas. (LEE, 2013) Desta forma novas faces, pontos de vista e histórias se descortinariam aos olhos do julgador. Neste sentido Hansas, defende que a empatia, ainda que não deva ser o principal recurso usado em uma decisão judicial, é necessária para que os juízes realizem seu trabalho adequadamente "porque eles seriam incapazes de fazer julgamentos inteligentes sobre como a lei deve ser aplicada sem a habilidade de julgar seus efeitos nos humanos sujeitos à esta decisão. E isso requer a habilidade de se colocar no lugar das partes e ver a situação de sua perspectiva." ${ }^{11}$ (HANSAS, 2011, p. 43, tradução nossa)

\footnotetext{
${ }^{10}$ Neste sentido, Colby (2012): “Consequentemente, ao atribuir peso aos interesses das várias partes no curso da elaboração ou aplicação da doutrina jurídica, os juízes são naturalmente inclinados a ter empatia - e isso valorizar mais - os sentimentos e tensões daqueles cujas circunstâncias e experiências mais se assemelham a sua própria” (p. 1990, tradução nossa)

${ }^{11}$ No texto original: "this is because they would be unable to make inteligent judgments about how the law should be Applied without the ability to judge its effects on the human beings subject to it. And this requires the ability top ut oneself in their place and view the decision from their perspective."
} 
Este esforço, potencializado com a leitura, em compreender a perspectiva dos envolvidos, ou seja, de ter empatia com aquele cuja vida é distinta de quem julga, é a chave para se obter um julgamento empático cujo predomínio seja da modalidade cognitiva, a qual permite ao julgador considerar os pontos de vista mais diversos que se apresentarem. Hansas (2011) destaca que esta interpretação da legislação é a medida correta de seu uso, com a ressalva de que não deve se adentrar na seara da aplicação da lei. Acerca da interpretação e da necessidade do esforço empático, Lee (2013) sustenta que na ausência da tentativa constante de ampliação dos pontos de vista considerados, as identificações automáticas com as partes e situações ocorrem, simplesmente reafirmando a perspectiva individual do julgador. Assim, se dá um afastamento da imparcialidade justamente por não ocorrer um julgamento empático.

Neste ponto, tão abordados por aqueles autores que condenam a utilização da empatia, fica expressa a divergência de posicionamentos. Enquanto aqueles apontam a reafirmação de noções pré-concebidas como um aspecto negativo do julgamento empático, Lee (2013) demonstra como o esforço do julgador em conhecer diferentes perspectivas, o que somente é possível por meio da empatia, garante sua desvinculação em face dos preceitos individuais que anteriormente carregava consigo.

Ainda, destaca-se o conceito de "moral imagination" (BANDES, 2011) também seria útil em sua utilização, uma vez que afasta o julgador da realidade que se apresenta mais facilmente aos seus olhos. Hansen (2011) dialogando com este conceito, defende que sua utilização é o que possibilita a consideração de várias possíveis consequências que podem se derivar de uma decisão judicial. A definição da imaginação moral auxilia na compreensão de como pode ser utilizada para tornar mais eficaz a aplicação da empatia na decisão judicial:

\footnotetext{
“A imaginação moral é a capacidade de compreender as próprias limitações, as limitações da perspectiva, a gama de valores em jogo e as possibilidades de mudança inerentes à situação. É a capacidade de compreender que as coisas podem ser ordenadas de maneira diferente, é uma saída do formalismo árido e dos sistemas fechados ${ }^{12} \%$. (BANDES, 2011, p. 24, tradução nossa)
}

Para além do necessário esforço individual dos julgadores, uma outra forma extremamente necessária de ampliar as visões de mundo daqueles que julgam é pela

\footnotetext{
12 Trecho não traduzido: "Moral imagination is the ability to understand one's own limitations, the limitations of perspective, the range of values at stake and the possibilites pfor change inherent in the situation. It is the ability to understand that things might be ordered differently, a way out of arid formalism and closed systems."
} 
diversidade na composição do judiciário ${ }^{13}$, ainda que enfrente diversas limitações e questionamentos acerca de sua efetividade para tal função em virtude do silenciamento das diferenças, como será estudado a seguir. Esta composição plural poderia facilitar (não substituir) a utilização da empatia por permitir que os pontos cegos daqueles que julgam não sejam sempre os mesmos em virtude de suas origens e experiencias de vida similares:

\begin{abstract}
Obviamente, uma maneira de garantir que os interesses de outros grupos sejam compreendidos e valorizados nos tribunais é procurar garantir que mais membros desses grupos tenham a oportunidade de servir como juízes. Uma vez que eles também tenderão naturalmente a ter mais empatia por pessoas como eles, o judiciário levará seus interesses em consideração na tomada de decisão simplesmente dando-lhes um assento no banco. Essa é de fato a motivação por trás de grande parte do apelo por uma maior diversidade no judiciário. ${ }^{14}$ (COLBY, 2012, p. 2002, tradução nossa)
\end{abstract}

Embora não se entenda que a empatia deva ser a única motivação para a composição de um judiciário mais plural, ao menos não a motivação principal, serão analisadas a seguir a necessidade e os benefícios que poderiam ocorrer caso fosse, de fato, colocada em prática, considerando a realidade do silenciamento das diferenças. Tal realidade fica muito explícita no cenário brasileiro, como se verá adiante.

\title{
4 EMPATIA COMO NECESSIDADE
}

Maria Tereza Sadek (2011) defende que conhecer quem são os juízes brasileiros implica em saber mais do que literalmente a composição do judiciário, aqui, da classe dos magistrados. Este, a partir do momento que possui a capacidade de verificar e controlar a constitucionalidade das leis e dos outros poderes, se torna verdadeiro poder de estado. Assim, ganham papel relevante na arena pública e merecem, portanto, ter investigadas sua composição, origem, formas de decidir.

\footnotetext{
${ }^{13}$ Destaca-se ressalva feita por Severi (2016, p. 106): "Um Judiciário democrático envolve não apenas a diversidade no acesso à justiça, mas também que ele tenha uma composição que seja reflexo, o mais possível, da sociedade, em termo de diversidade de gênero, sexualidade, étnico-racial e de classe social. Se, por um lado, não dá para supor que as mulheres façam uma melhor defesa do direito das mulheres, por outro, não é possível conciliar a persistência de uma estrutura desigual e hierarquizada na Magistratura com os marcos constitucionais de uma sociedade democrática."

${ }^{14}$ No trecho original: "Of course, one way to seek to ensure that the interests of Other groups will be understood and valued in the courts is to seek to ensure that more members of those groups are given the opportunity to serve as judges. Since they, too, will naturally tend to empathize more with people like themselves, the judiciary will take their interests into account in decision making simply by giving them a seat oh the bench. That is indeed the motivation behind Much of the call for greater diversity in the judiciary."
} 
A partir da enorme relevância, conforme expresso pela autora, que a identificação de quem é o juiz carrega, busca-se entender a composição da classe dos magistrados no que diz respeito à gênero, raça, grau de escolaridade e demais características abaixo estudadas para poder entender qual é o padrão do juiz brasileiro, de acordo com estes critérios. Considerando esta percepção, relacionar os dados obtidos com a necessidade dos julgamentos serem feitos com a utilização da empatia cognitiva, de modo que diversas realidades sejam levadas em consideração por quem julga, chegando, portanto, a um resultado justo.

No último Censo do poder Judiciário realizado pelo Conselho Nacional de Justiça acerca da composição do judiciário, traçou-se o perfil dos servidores e dos magistrados brasileiros. A pesquisa teve a coleta de dados realizada via survey na segunda metade do ano de 2013 e seus resultados foram apresentados em 2014. Em virtude da temática do presente artigo se voltar à análise acerca da necessidade de empatia na tomada de decisão judicial, serão desconsiderados os dados referentes aos servidores públicos.

A classe de magistrados composta na época por 16.812 magistrados em atividade participou do Censo na proporção de 64\%, 10.796 juízes e juízas responderam ao questionário tornando possível traçar o perfil da classe. Nesta empreitada, o censo teve como objetivo desvendar dados acerca das seguintes categorias:

\footnotetext{
Para alcançar seu objetivo de traçar o perfil dos magistrados e dos servidores do Poder Judiciário, o Censo buscou conhecer quem são e o que pensam, identificar os níveis de satisfação com as políticas institucionais das instituições que trabalham e sobre o próprio Conselho Nacional de Justiça, além de buscar, pela primeira vez, quais os níveis de motivação com a carreira, com a escolha profissional de trabalhar no poder judiciário. (CNJ, 2014, p. 7)
}

Em virtude do recorte dado ao tema, serão considerados os dados atinentes ao tópico de "quem são" os magistrados brasileiros. Pretende-se verificar se a composição desta classe (homogênea ou não) pode se beneficiar do uso da empatia cognitiva como capacidade de consideração dos diversos pontos de vista que se apresentam. Assim, serão considerados os dados gerais referentes às Informações Pessoais (capítulo 3. Magistrados: quem são e o que pensam, Item 3.1 Informações Pessoais) a fim de traçar um perfil geral de quem é o magistrado brasileiro.

Já no ano de 2018 foi realizada nova pesquisa, cujos dados serão utilizados na presente análise. Neste estudo, também pelo Conselho Nacional de Justiça, objetivou-se traçar o perfil Sociodemográfico dos magistrados brasileiros. Este teve participação de 11.348 
magistrados, representando um 62,52\% da classe, pouco inferior à participação apresentada no Censo, mas ainda em uma proporção bastante relevante. Serão comparados os dados atinentes aos magistrados informados pela pesquisa de 2018 nas mesmas categorias gerais que correspondem às existentes Censo, a fim de entender se o perfil do juiz brasileiro segue sendo o mesmo.

Com relação à idade média dos juízes e juízas, o censo, em seu item 3.1.1.4 ${ }^{15}$, realiza uma separação entre os Tribunais brasileiros e aponta a idade média do total dos Tribunais: 44,7 anos é a idade média do magistrado brasileiro. Destes juízes, 64,1\% são do sexo masculino e $35,9 \%$ do sexo feminino ${ }^{16}$. Já a pesquisa sobre o Perfil Demográfico (2018) indicou que a idade média dos juízes é de 47 anos, e que as juízas mulheres representam um total de 38\% da magistratura (CNJ, 2018, p. 8). Há uma prevalência de homens juízes com idade na casa dos quarenta anos. Nota-se que pequenas e discretas alterações ocorreram no tocante a estes dados nos períodos estudados. Destaca-se que as mulheres são mais presentes nas carreiras iniciais da magistratura, e esta baixa mobilidade pode indicar um "teto de vidro" ${ }^{" 17}$ para sua ascensão profissional (BONELLI, 2011)

Já com relação à cor/raça, dos Tribunais em geral, o Censo aponta que 84,2\% dos juízes são brancos, $15,6 \%$ negros e $0,1 \%$ indígenas ${ }^{18}$. Esta situação se altera de forma discreta nos dados de 2018, uma vez que 80,3\% dos juízes se declararam brancos, 18,1\% negros, 1,6\% asiáticos e 11 juízes se declararam indígenas (CNJ, 2018, p. 8). A prevalência de magistrados brancos em todas as instâncias faz concluir que a ideia do teto de vidro não pode ser aplicada ao quesito racial. Pessoas não brancas não possuem entraves somente para ascender na carreira de juiz, mas para ingressar na magistratura propriamente dita. No sentido deste entendimento, segue trecho:

\footnotetext{
${ }^{15}$ Idade média dos magistrados segundo ramos de Justiça. Brasil, 2013. p.34

${ }^{16}$ Tópico 3.1.2.4 Percentual de magistrados segundo ramos de Justiça, por sexo. Brasil, 2013, p. 37.

${ }^{17}$ Acerca do teto de vidro, figurando como barreira invisível, explica SEVERI (2016, p. 93): ‘[...] Até o momento, as mulheres ainda continuam sendo promovidas de forma mais lenta que os homens e que é pouco provável que a simetria entre os gêneros no recrutamento e a promoção dos membros do Judiciário ocorra de forma espontânea, sem que as barreiras invisíveis sejam superadas à luz de análises sobre os diversos tipos de formações sociais e de relações de poder que constituem as categorias de gênero, raça--- etnia e classe social."

${ }^{18}$ Segundo a categoria "total" do tópico 3.1.3.6 Percentual de magistrados segundo cor/raça, por ramos de Justiça. Brasil, 2013, p. 42. Destaca-se nota de rodapé referente a este item: "Nos gráficos 3.1.3.1, 3.1.3.2, 3.1.3.3 e 3.1.3.6 desta seção, a categoria "brancos" engloba os servidores que se declararam "brancos" e os que se declararam "amarelos"; e a categoria "negros" engloba os servidores autodeclarados "pretos" e "pardos", p. 38
} 
Quando o critério é raça, portanto, a desigualdade é ainda maior. Enquanto no caso das mulheres fala-se na existência de um teto de vidro, que as impede de ascender aos cargos mais elevados das carreiras profissionais, no caso dos negros o impedimento não diz respeito apenas à ascensão na carreira, mas ao próprio ingresso. (DE OLIVEIRA; PEREIRA, 2018, p. 2019)

No tocante ao estado civil, 8.467 magistrados são casados (as) ou vivem em união estável com pessoas do outro sexo ${ }^{19}$, representando a proporção de 78,4 \% da magistratura. $11,4 \%$ são solteiros, $7,2 \%$ divorciados, $1,2 \%$ separados judicialmente, $1,1 \%$ casados ou em união estável com pessoas do mesmo sexo e $0,6 \%$ são viúvos. ${ }^{20}$ Já o Perfil Demográfico de 2018 aponta que $80 \%$ dos magistrados são casados ou vivem em união estável (sem indicação do sexo do cônjuge), $9 \%$ são divorciados ou separados, $10 \%$ solteiros e $1 \%$ viúvos ${ }^{21}$. Em mais uma categoria não há alterações bruscas nas proporções dominantes de composição da magistratura brasileira. Os magistrados são, em sua maioria, casados ou possuem união estável.

Ainda acerca das Informações Pessoais, o Censo apresenta os dados que seguem. Dentre os magistrados, $88,9 \%$ não possui mais de um curso superior ${ }^{22}$ e o curso superior de Direito foi cumprido por $51,2 \%$ dos juízes em Instituição Particular de Ensino, ${ }^{23}$ porcentagens esta que se mantém quase inalteradas de acordo com o Perfil Demográfico ${ }^{24}$. Acerca da escolaridade no geral o Censo indica que $65,2 \%$ dos juízes realizaram algum tipo de pósgraduação $^{25}$, proporção esta aumentada no Perfil Demográfico de 2018 no qual constatou-se que quase $70 \%$ dos magistrados se encontravam nestas condições.

Considerando a maioria ${ }^{26}$ apresentada em cada uma das categorias citadas, é possível traçar o perfil médio de quem é o magistrado brasileiro: são, no geral, juízes; brancos; casados

\footnotetext{
${ }^{19}$ Item 3.1.5.1 Número e percentual de magistrados segundo estado civil. Brasil, 2013, p. 47

20 3.1.5.2. Percentual de magistrados segundo estado civil e percentual de magistrados segundo sexo e estado civil. Brasil, 2013, p. 47

${ }^{21}$ Figura 7: Estado Civil de acordo com o sexo, em percentual. DP/CNJ, 2018, p. 11

22 3.1.6.2. Percentual de magistrados que fizeram ou não mais de um curso superior de graduação, segundo ramos de Justiça.

Brasil, 2013, p. 49

${ }^{23}$ 3.1.6.3. Percentual de magistrados segundo tipo de instituição em que concluiu o curso de direito, por ramos de Justiça. Brasil,

2013, p. 50.

${ }^{24}$ Segundo o Perfil Demográfico, 51\% dos magistrados obteve título de Bacharel em Direito em Instituições de Ensino Privadas e 89,2\% dos magistrados possui somente graduação em direito.

25 3.1.6.1. Percentual de magistrados segundo escolaridade, por ramos de Justiça. Brasil, 2013, p. 48.

26 Não necessariamente a maioria absoluta, mas sim o grupo predominante em cada categoria dentre as formuladas pelo Censo.
} 
ou em união estável; com idade média 47 anos (CNJ, 2018); formados em um único curso superior, Direito, em Instituição Particular; possuem pós-graduação em direito e são homens.

Mesmo que seja possível transitar dentre as características dominantes no grupo de magistrados obtendo perfis diferentes, é possível afirmar haver uma homogeneidade em diversas categorias. Exemplifica-se: a maioria absoluta dos magistrados é composta por homens brancos. Assim, se torna possível inferir que em virtude deste simples recorte, há uma padronização das experiencias sociais vividas por esta classe, sem, contudo, colocar sob questionamento a pluralidade de vivencias pessoais.

Contudo, apesar de haver esse grande bloco de juízes oriundos dos mesmos marcadores sociais, não se pode tornar invisível, ainda que ocorra em pequena parcela, a existência de magistrados e magistradas que não integram o perfil dominante, o que pode ser entendido, sobretudo quando comparado a histórica composição do judiciário brasileiro, como uma composição heterogênea da classe de magistrados.

A respeito desta possibilidade de análise, Bonelli (2011) expõe que é possível entender, sobretudo no que diz respeito às diferenças de gênero, uma composição mais heterogênea da magistratura brasileira. Explica como essa característica é silenciada, sendo que somente se considera existente na oportunidade de reafirmar seu apagamento: "A diferença como subjetividade é vocalizada entre aqueles que procuram ativamente apagar a externalização dela buscando neutralizar marcadores que subordinam, como os estereótipos de gênero". (BONELLI, 2011, p. 121). Contudo, destaca que apesar da tentativa de neutralização, ainda há a atribuição destes estereótipos às juízas.

Visando reduzir essa diferenciação e reforçando a ideia da classe dos juízes como homogênea, a concepção do profissionalismo na magistratura passa a ser valorizada. Por meio da reafirmação do perfil técnico e profissional do juiz, as consequências desta heterogeneidade na composição do judiciário acabam se perdendo. Ou seja, silencia-se qualquer possibilidade de identificação entre uma forma de julgar e o fato de ser mulher, na tentativa de restabelecer a homogeneidade da classe em algum grau, apesar de sua composição com maior variação dente os integrantes (BONELLI, 2010).

Entende-se que alguns fatores, tal qual o ensino jurídico, podem auxiliar nessa busca pela homogeneidade por meio de um profissionalismo que essencialmente apaga o gênero em razão, como aponta Almeida (2018), da educação jurídica ensinar predominantemente valores masculinos: 
Vale lembrar, nesse sentido, que o ideal de profissionalismo no Judiciário está muito atrelado à ideia de neutralidade. Trata-se de uma noção que faz parte do ethos do juiz - ou pelo menos de um bom juiz, ou de um juiz "ideal" - mas que está carregada de viés cultural. Assim, um debate sobre um sistema de Justiça mais democrático não pode deixar de refletir sobre a ideia de neutralidade que temos, e nem sobre o ensino jurídico que atualmente é praticado, e que, muitas vezes, reflete valores masculinos. (ALMEIDA, 2018, p. 124)

Há ainda, pesquisas que confirmam haver a tentativa de neutralização de características que fogem deste padrão dominante do que se observa dentro da magistratura. Severi (2016) destaca em pesquisa realizada com juízas do TJPA, Tribunal este que concentra a maior proporção de juízas mulheres do Brasil, as entrevistadas relataram esforços para que não houvesse percepção de "traço de gênero" em suas decisões, com o principal receio de poder ser associado à parcialidade. Ora, reitera-se com mais este exemplo que a discreta heterogeneidade existente na composição do judiciário brasileiro, não impede de haver um padrão dominante de quem é magistrado, como também acaba se submetendo à lógica do profissionalismo e do apagamento do que poderia trazer uma voz diferente, ocorrendo, nos termos da autora um processo de homogeneização das diferenças - sobretudo em instâncias superiores.

E por conta destas duas grandes interpretações distintas que se pode fazer da composição da magistratura brasileira é que se reforça a hipótese de que os juízes brasileiros devem ser, na medida do possível, mais empáticos. Esta homogeneidade verificada relacionase às partes iniciais deste artigo no tocante à capacidade empática como sendo o garantidor de uma decisão imparcial. Para poderem considerar perspectivas distintas das vividas, o que, como defende Lee (2013), garante um julgamento imparcial, os juízes brasileiros precisam, novamente, serem empáticos. Isto é, considerando a definição cognitiva de empatia, que justamente por ser uma capacidade cognitiva pode ser trabalhada e desenvolvida e que se faz necessária para evitar que o juiz caminhe pelos vieses, os quais vem de forma irrefletida e fazem com que se julgue com base em crenças pré-existentes do próprio julgador:

Sem uma tentativa de compreender o ponto de vista oposto, os juízes que ainda são predominantemente privilegiados e do sexo masculino podem interpretar mal o significado de vários fatos, como o tratamento em um ambiente de trabalho ou a impressão causada por uma exibição religiosa. Desse modo, a empatia pode motivar 
os tomadores de decisão a questionar seus preconceitos e preconceitos irrefletidos. (p. NEGOWETTI , 2014, 750/751, tradução nossa) ${ }^{27}$

Destaca-se o pensamento de Bandes (2011), segundo o qual, ainda que seja improvável traçar um caminho seguro para levar os juízes a decidirem com a utilização da empatia cognitiva, é necessário realizar esforços para redução dos pontos-cegos daqueles que julgam. Assim, entende a autora que uma possibilidade mais realista reside no esforço dos magistrados em se tornarem atentos às suas reações face ao apresentado pelas partes, bem como interessados em buscar informações adicionais quando necessário para confrontar suas noções pré-concebidas. Para a autora, a imaginação moral, já mencionada como um recurso para haver adequada utilização da empatia, auxilia nesta tarefa.

Considerando a composição do judiciário brasileiro em sua classe de magistrados, marcada por tamanha predominância de determinados grupos, e o caráter lento e gradual de sua diversificação sociodemográfica, torna-se evidente a necessidade de que seus juízes se esforcem em serem mais empáticos. Ou seja, que a empatia cognitiva seja uma capacidade a ser desenvolvida e que garante a consideração de diversas perspectivas diferentes das de quem julga: "Empatia é uma capacidade que pode ser aprendida e melhorada. Seus requisitos são a atenção à perspectiva parcial e a curiosidade e o incentivo para expandi-las"28 (BANDES, 2011, p. 15). Seria este, na composição atual do judiciário, um ótimo recurso para a diminuição dos pontos cegos que existem em virtude de tantas semelhanças na composição de um mesmo grupo.

\section{CONCLUSÃO}

O presente artigo teve como objetivo analisar argumentos favoráveis e contrários à utilização de empatia cognitiva na tomada de decisão judicial, ou seja, se devem ou não os juízes serem empáticos. Mais especificamente, buscou-se verificar, com base nos pontos apresentados, se a empatia deve estar presente neste contexto a partir de análise realizada acerca da composição da magistratura brasileira.

\footnotetext{
${ }^{27}$ No original: "Without na attempt to understand the opposing viewpoint, judges who still are predominantly privileged and male, may misread the significance od various facts sucha as treatment in a work environment or the impression made by a religious display. In this way, empathy can motivate decision-makers to question theirs unreflective biases and preconceptions".

${ }^{28}$ No trecho original: "Empathy is a capacity that can be learned and improved, The preconditions are an awareness of partial perspective and the curiosity and the incentive to expand it."
} 
Como argumento contrário à sua utilização, tem-se que a empatia pode ser entendida como elemento facilitador da utilização de vieses e de noções pré-existentes, sendo neste caso aplicada em sua vertente afetiva e comprometendo a parcialidade de quem julga. Em contraposição, seu uso pode ser entendido essencial por ser um elemento que pode garantir a dita imparcialidade, uma vez que seria o que faz o magistrado levar em conta pontos de vista distintos do seu, garantindo que as diversas narrativas sejam consideradas de forma a tornar possível uma decisão justa. Segundo esta posição, a que entende a empatia como uma capacidade cognitiva, o juiz decidiria de forma mais adequada se a utilizasse. Por ser uma capacidade, pode ser desenvolvida, sendo a leitura para contato com realidades distintas uma das ferramentas disponíveis para isto ocorrer, conforme defendido por Lee (2013). Ademais, ferramentas como a imaginação moral (BANDES, 2011) auxiliaria na correta aplicação da empatia, sem macular a imparcialidade do juiz.

Por fim, analisando a composição da magistratura brasileira, em termos gerais, com base nos dois últimos levantamentos realizados pelo Conselho Nacional de Justiça (2014 e 2018), conclui-se que a classe dos magistrados pode ser analisada como homogênea ou como heterogênea. Quando entendida como um bloco, é em razão de haver um padrão dominante de pessoas com características comuns que ocupam a magistratura. Já quando entendida da segunda forma, é em razão de haver uma maior diversidade na composição do judiciário, sobretudo quando comparado com o histórico deste grupo. Destaca-se que nesta segunda análise, pesquisas como a de Bonelli (2010 e 2011) e Severi (2016) evidenciam haver ainda uma nova formação de bloco dentro da magistratura. Isto ocorre em razão, conforme apontam estes estudos, do silenciamento das diferenças e da visão de profissionalização que cerca a carreira. Assim, ainda quando há a possibilidade desta composição mais plural ter efeitos relacionados à diferentes perspectivas dos magistrados, verifica-se uma redução, quando não extinção destes traços poderem marcar as decisões.

Considerando as duas formas de interpretar, bem como a exposição inicialmente realizada acerca das vantagens de se decidir utilizando a empatia cognitiva, conclui-se que no caso da magistratura brasileira, onde há um padrão de quem é juiz e de como a classe de magistrados deve pensar, os juízes devem, na medida do possível, serem mais empáticos, especialmente naqueles casos em que decidem interesses de pessoas distintas de seu grupo social, ou seja, que não sejam brancas, casadas, homens e da classe média e alta. 


\section{REFERÊNCIAS}

ALMEIDA, Fernanda Andrade. A diversificação do poder judiciário e os efeitos do gênero na administração da Justiça. Revista Jurídica - CCJ. v. 22, nº . 47, p. 111-128, jan./jun. 2018.

BANDES, Susan A. Moral Imagination in Judgind. Washburn Law Journal, v. 51, p. 1-24, 2011.

BONELLI, Maria da Gloria. Magistrados (as) e promotores(as): profissionalismo e gênero.

(In) Pesquisa empírica em direito. Coordenação e organização: Alexandre dos Santos Cunha e Paulo Eduardo Alves da Silva - Rio de Janeiro: Ipea, 2013.

Profissionalismo e diferença de gênero na Magistratura paulista. Civitas, V. 10, p. 270-292, mai/ago. 2010. Disponível em:

Profissionalismo, gênero e significados da diferença entre juízes e juízas estaduais e federais. Contemporânea-Revista de Sociologia da UFScar, v. 1, n. 1, p.103-123, 2011.

COLBY, Thomas B. In defense of judicial empathy. Minnesota Law Review, v. 96, p.19442015, 2012.

CONSElHo NACIONAL DE JUSTIÇA (CNJ). Censo do Poder Judiciário. VIDE: Vetores Iniciais e Dados Estatísticos. Brasília: CNJ, 2014. Disponível em: https://www.cnj.jus.br/wpcontent/uploads/2011/02/CensoJudiciario.final.pdf. Acesso em 26 jan. 2021.

Perfil Sociodemográfico dos Magistrados Brasileiros 2018. Brasília: CNJ, 2018.

Disponível em: https://www.cnj.jus.br/wpcontent/uploads/2019/09/a18da313c6fdcb6f364789672b64fcef_c948e694435a52768cbc00bd a11979a3.pdf. Acesso em 26 jan. 2021.

CUFF et. Al. Empathy: a review of the concept. In: Emotion Review, vol. 8, n. 2, pp. 144153, apr. CUFF ET ALL 2014.

DE OLIVEIRA, Renan Medeiros; PEREIRA, Jane Reis Gonçalves. A (des)igualdade no Judiciário brasileiro: breve comentário ao relatório "Perfil Sociodemográfico dos Magistrados Brasileiros", do Conselho Nacional de Justiça. Revista Publicum. Rio de Janeiro, v. 4, n. 2, 2018, p. 214-219.

HANSAS, John. Is Moral Imagination the Cure for Misapplied Judicial Empathy? Bandes, Bastiat and the Quest for Justice. Washburn Law Journal, v. 51, n. 1, p. 25-48, 2011. 
LEE, Rebecca K. Judging Judges: Empathy as the Litmus Test for Imparciality. University of Cincinnati Law Review, v. 82, p. 145, 2013.

LOW, Gary. Emphatic plea for the empathic judge. (2018). Singapore Academy of Law Journal. 30, p. 97-118. Research Collection School Of Law.

NEGOWETTI, Nicole E. Judicial Decisionmaking, Empathy, and the Limits od Perception. Akron Law Review, v. 47, n. 3, p. 693-752, 2014.

PRINZ, Jesse J. Against Empathy. The Southern Journal of Philosophy, v. 49, Spindel Supplement, 2011a.

Is Empathy Necessary for Morality?. In: COPLAN, A; GOLDIE, P. (eds.).

Empathy: Philosophical and Psychological Perspectives. Oxford University Press. p. 211$229,2011 b$.

SADEK, Maria Tereza. Magistratura: Imagem em movimento. (In) Pesquisa empírica em direito. Coordenação e organização: Alexandre dos Santos Cunha e Paulo Eduardo Alves da Silva - Rio de Janeiro: Ipea, 2013.

SEVERI, Fabiana Cristina. The court of gender and the problem of effective human rights of women/ O gênero da justiça e a problemática da efetivação dos direitos humanos das mulheres." Direito e Práxis, vol. 7, no. 1, 2016, p. 80+. Gale Academic OneFile.

STRUCHINER, Noel. No Empathy Towards Empathy: Making the Case for Autistic Decision-Making.

STRUCHINER, Noel; TAVARES, Rodrigo de Souza. Direito \& Emoções: uma proposta de cartografia. In: STRUCHINER, Noel; TAVARES, Rodrigo de Souza. Novas Fronteiras do Direito: Da Filosofia Moral à Psicologia Experimental. Rio de Janeiro: PoD: PUC-Rio, 2014. 